\title{
Reply to Drs. Kiaei and Molinaro Regarding the Publication "Comparison of a Bridge Immunoassay with Two Bioassays for Thyrotropin Receptor Antibody Detection and Differentiation"
}

\section{Dear Editor,}

Drs. Kiaei and Molinaro [1] put forth two criticisms of the manuscript published by us [2]. They state that the experimental design of this study is flawed and that the authors falsely claim that negative Thyretain ${ }^{\mathrm{TM}}$ TSI Reporter BioAssay results for two Graves' diseases patients undergoing drug treatments means the absence of stimulating antibodies. To substantiate this claim Drs. Kiaei and Molinaro point out that the manufacturer of the Thyretain TSI Reporter BioAssay clearly states in the package insert that " $[t]$ he effects of various drug therapies on the performance of this Kit have not been established" [1]. Second, the package insert explicitly states that "[a] negative result does not exclude the possibility of the presence of TSI" and results of the test should be interpreted in conjunction with information available from other clinical information, such as physical symptoms and thyroid hormone testing, as recommended by the American Thyroid Association (ATA)". Furthermore they state that the "authors of the manuscript did not consider the manufacturer's warning regarding the intended patient population and the ATA guidelines regarding the interpretation of the test results in conjunction with other clinical information. Instead, the authors based their conclusions on the negative Thyretain TSI Reporter BioAssay results and ignored the patients' clinical history of Graves' disease."

\section{Authors' response}

The problem with these criticisms is that the intended use of the Thyretain TSI Reporter BioAssay and any statement in the package insert apply to the use of the Bioassay during the course of patient management in a clinical setting. The purpose of this study [2] and that of numerous other published studies [3-5] is to evaluate various TSH-R antibody assays to better understand their performance and clinical utility. This is a research study and the results are not being used to manage individual patients but rather to better understand how results from different TSH-R Ab assays could be interpreted. The patient population used for the study was well-described in Table 1 in reference [2].

In their second criticism, Drs. Kiaei and Molinaro state that our analysis of the data is inaccurate. They state that we fail to mention or consider, the fact that the Thyretain TSI Reporter BioAssay reports net stimulating activity as documented in previous publications by some of the authors of this study. Although blocking antibodies do not generate a signal in the Thyretain TSI Reporter BioAssay, blocking antibodies, when present, interfere with that assay's measurement of stimulating antibodies. As such, the assay reports "zero" net stimulating activity for samples containing equal activity of stimulating and blocking antibodies. Therefore, it is possible that stimulating antibodies were present in the patient samples despite the negative result reported by the Thyretain TSI Reporter BioAssay.

\section{Authors' response}

The presence of anti-TSH-R blocking antibodies in patients with autoimmune thyroid disease is a well-established phenomenon supported by a large body of literature $[6,7]$. The tertiary referral thyroid lab at the Johannes Gutenberg University (JGU) Medical Center, Mainz, Germany has considerable experience in testing for blocking antibodies [8-11]. The JGU lab has observed the presence of blocking TSHR-Ab both prior to starting an ATD treatment as well as during the medical management of the thyroid dysfunction. The CE-marked Thyretain TBI bioassay has been well-characterized and has performed well in identifying blocking antibodies in patients with GD and HT $[9,10]$.

Despite the hypothetical possibility that a patient could have both stimulating and blocking antibodies that could cancel each other out in bioassays, there is no direct experimental evidence of such an effect when testing patient serum. It is true that the Thyretain TSI Reporter BioAssay measures net stimulatory activity and this is, in fact, phys- iologically relevant because the thyroid gland responds to net stimulatory activity. In this context, it is correctly stated by the authors of the letter that small amounts of a monoclonal TSAb (M22) in the presence of higher amounts of a monoclonal TBAb (K170) result in a negative result in the Thyretain TSI Reporter BioAssay [12]. In our present study, the samples that were negative in the Thyretain TSI Reporter BioAssay, but positive in the blocking bioassay, had net blocking activity. The fact that these samples were positive in the IMMULITE ${ }^{\circledR}$ 2000/2000 XPi TSI (bridge immunoassay) is interpreted by Drs. Kiaei and Molinaro as being TSI positive because the bridge immunoassay is purported to be TSI specific. There is, however, no evidence that the bridge immunoassay is specific for stimulating TSH-R $A b$. The bridge immunoassay is a novel binding assay designed to detect bridging of two TSH-R fragments following binding by an anti-TSH-R antibody. It was designed using a mutated form of the TSH-R referred to as MC4. This MC4 molecule was initially thought to bind only to stimulating antibodies. There is, however, significant published evidence that demonstrates that blocking antibodies bind to the MC4, and, in fact, the MC4 molecule is used in the well-characterized Thyretain TBI bioassay that detects blocking antibodies $[8,11]$. The sequence of the MC4 molecule originally constructed by the Kohn group (GenBank Accession number M63925) and used for the Thyretain TSI Reporter BioAssay was published [13]. There is, however, uncertainty regarding the sequence of the MC4 molecules used in the IMMULITE 2000/2000 XPi TSI assay and it would be useful for it to be made public. It is noteworthy that in the $510(\mathrm{k})$ submission to the FDA (K152061, July 24, 2015), it is stated that the IMMULITE 2000/2000 XPi TSI assay..."employs two recombinant chimeric human TSH receptors (hTSHR) where the major epitope for the blocking antibody is replaced." It is not clear if this represents two different 'MC4' molecules and whether this could influence anti-TSH-R antibody recognition. Regardless, since the TSAb and TBAb antibody recognition sites have not been 
fully defined, there is no evidence that supports the notion that the major epitope for blocking antibody could be replaced as claimed.

Furthermore, there is experimental evidence that the IMMULITE 2000/2000 XPi TSI assay is not TSI specific. For example, a human monoclonal TSH-R Ab (K1-70) that is purely blocking is positive in the bridge immunoassay [14]. In addition, a number of serum samples that are positive in a blocking bioassay (i. e. have net blocking activity) have tested positive in the IMMULITE 2000/2000 XPi TSI assay as well as other anti-TSH-R binding assays $[12,15]$. These empirical data lead us to conclude that it is far more likely that the IMMULITE 2000/2000 XPi TSI assay is not specific for TSI rather than that the TSI bioassay results were false negative. In our opinion, to be able to interpret that samples that are positive in the IMMULITE 2000/2000 XPi TSI assay and positive in a blocking bioassay as positive for both TSI and TBI requires experimental evidence that the IMMULITE 2000/2000 XPi TSI assay is actually specific for TSI. To our knowledge, such evidence has not been published. We conclude, therefore, that the IMMULITE 2000/2000 XPi TSI is most likely not specific for the detection of TSAb.

Another concern that has been raised is that testing for blocking antibodies in the presence of stimulatory antibodies may give false positive results due to the possibility that TSI may have partial antagonist activity which may be interpreted as blocking activity. This hypothetical possibility has never been demonstrated directly. In addition, in our experience, almost all patients who are positive for TSI test negative in the blocking bioassay, which suggests that partial antagonist activity of TSI is rare and/or that the blocking bioassay, as designed, does not detect partial antagonist activity.

In conclusion, although we cannot exclude that TSAb and TBAb might co-exist in our two initially hypothyroid patients, there is no evidence to support the idea that the TSAb antibodies are specifically recognized by the IMMULITE 2000/2000 XPi TSI assay. Clinically more relevant are, however, the TBAb present in these patients' serum which, in our opinion, are also being detected in the IMMULITE 2000/2000 XPi TSI assay.

\section{References}

[1] Kiaei D, Molinaro R. A Negative Thyretain TSI bioassay result does not exclude the possibility of the presence of TSI. Horm Metab Res 2020; 52: 124-125

[2] Allelein S, Diana T, Ehlers M et al. Comparison of a bridge immunoassay with two bioassays for thyrotropin receptor antibody detection and differentiation. Horm Metab Res 2019; 51: 341-346

[3] Leschik J], Diana T, Olivo PD et al. Analytical performance and clinical utility of a bioassay for thyroid-stimulating immunoglobulins. Am J Clin Pathol 2013; 139: 192-200

[4] Kahaly G], Diana T, Glang J et al. Thyroid stimulating antibodies are highly prevalent in hashimoto's thyroiditis and associated orbitopathy. J Clin Endocrinol Metab 2016; 101: 1998-2004

[5] Kahaly G], Wuster C, Olivo PD et al. High titers of thyrotropin receptor antibodies are associated with orbitopathy in patients with graves disease. J Clin Endocrinol Metab 2019; 104: 2561-2568

[6] Chiovato L, Vitti P, Lombardi A et al. Detection and characterization of autoantibodies blocking the TSH-dependent cAMP production using FRTL- 5 cells. J Endocrinol Invest 1987; 10: 383-388

[7] McLachlan SM, Rapoport B. Thyrotropin-blocking autoantibodies and thyroid-stimulating autoantibodies: potential mechanisms involved in the pendulum swinging from hypothyroidism to hyperthyroidism or vice versa. Thyroid 2013; 23: 14-24

[8] Li Y, Kim J, Diana T et al. A novel bioassay for anti-thyrotrophin receptor autoantibodies detects both thyroid-blocking and stimulating activity. Clin Exp Immunol 2013; 173: 390-397

[9] Diana T, Li Y, Olivo PD et al. Analytical performance and validation of a bioassay for thyroid-blocking antibodies. Thyroid 2016; 26: 734-740

[10] Diana T, Krause J, Olivo PD et al. Prevalence and clinical relevance of thyroid stimulating hormone receptor-blocking antibodies in autoimmune thyroid disease. Clin Exp Immunol 2017; 189: 304-309

[11] Diana T, Olivo PD, Kahaly G]. Thyrotropin receptor blocking antibodies. Horm Metab Res 2018; 50: 853-862

[12] Diana T, Wuster C, Olivo PD et al. Performance and specificity of 6 immunoassays for TSH receptor antibodies: a Multicenter Study. Eur Thyroid J 2017; 6: 243-249

[13] Lytton SD, Li Y, Olivo PD et al. Novel chimeric thyroid-stimulating hormone-receptor bioassay for thyroid-stimulating immunoglobulins. Clin Exp Immunol 2010; 162: 438-446

[14] Frank CU, Braeth S, Dietrich JW et al. Bridge technology with TSH receptor chimera for sensitive direct detection of TSH receptor antibodies causing graves' disease: analytical and clinical evaluation. Horm Metab Res 2015; 47: 880-888
[15] Diana T, Wuster C, Kanitz M et al. Highly variable sensitivity of five binding and two bio-assays for TSH-receptor antibodies. J Endocrinol Invest 2016; 39: 1159-1165

\section{Conflict of Interest}

TD has nothing to disclose. GJK consults for and the JGU Medical Center has received research-associated funding from Quidel. MS received from Siemens honoraria for oral presentations.

Authors

Stephanie Allelein ${ }^{1}$, Tanja Diana², Matthias Schott ${ }^{1}$, George J. Kahaly ${ }^{2}$

\section{Affiliations}

1 Medical Faculty, Division for Specific Endocrinology, University of Düsseldorf, Düsseldorf , Germany

2 Department of Medicine I, Molecular Thyroid Research Laboratory, Johannes Gutenberg University (JGU) Medical Center, Mainz , Germany

\section{Correspondence}

Matthias Schott MD, PhD
Medical Faculty
Division for Specific Endocrinology
University of Düsseldorf
Moorenstraße 5
40225 Düsseldorf
Germany
Tel.: + 49/211/81 04860,
Fax: + 49/211/8117860
matthias.schott@med.uni-duesseldorf.de

\section{Bibliography}

Horm Metab Res 2020; 52: 126-127

DOI 10.1055/a-1089-8026

ISSN 0018-5043

(c) 2020. The Author(s).

This is an open access article published by Thieme under the terms of the Creative Commons Attribution-NonDerivative-NonCommercial-License, permitting copying and reproduction so long as the original work is given appropriate credit. Contents may not be used for commercial purpose, or adapted, remixed, transformed or built upon. (https://creativecommons.org/licenses/bync-nd/4.0/)

Georg Thieme Verlag KG, Rüdigerstraße 14,

70469 Stuttgart, Germany

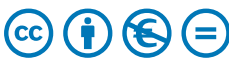

